\title{
Ecological effects of marine protected areas on rocky reef communities - a continental-scale analysis
}

\author{
Graham J. Edgar*, Rick D. Stuart-Smith \\ Tasmanian Aquaculture and Fisheries Institute, University of Tasmania, Private bag 49, Hobart, Tasmania 7001, Australia
}

\begin{abstract}
Data compiled by volunteer divers were utilised in a continental-scale investigation of ecological differences between reefs in no-take sanctuary zones in marine protected areas (MPAs) and adjacent fished zones. In a validation analysis, volunteer-generated data were found to be comparable to data obtained by scientific dive teams for all metrics investigated: estimated total number of species, total faunal abundance, mean fish size, and faunal composition of species sighted along transects. Variation between individual divers within volunteer and professional groups also contributed little to total estimated variance between transects compared to residual variation between replicate transects, variation between sites, and variation between regions studied. Sites in 11 MPAs distributed around $5000 \mathrm{~km}$ of the Australian coastline had significantly more large $(>30 \mathrm{~cm})$ fishes and total fish biomass than nearby fished reference sites. For the older MPAs, fishes belonging to the largest size class $(\geq 80 \mathrm{~cm}$ ) were observed approximately 10 times more often in sanctuary zones than in fished zones, while fishes in the smallest size class $(2.5 \mathrm{~cm})$ occurred at densities approximately 4 times higher in fished zones than in sanctuary zones. Results of our empirical field surveys contrast in several respects with outcomes of published meta-analyses. No overall differences in fish densities were evident between sanctuary zones and fished zones. The response of fish species richness to protection varied significantly between different MPAs, while invertebrate density and species richness were both significantly lower in sanctuary zones than in fished zones.
\end{abstract}

KEY WORDS: Effects of fishing · Marine reserve - MPA · Fishes · Macroinvertebrates · Species richness $\cdot$ Volunteer monitoring $\cdot$ Australia

\section{INTRODUCTION}

Little consensus exists in either public or scientific arenas on the net benefits and costs of marine protected areas (MPAs) for biodiversity conservation and fisheries management (Badalamenti et al. 2000, Walters 2000, Baelde 2005, Kaplan 2009, Le Quesne 2009). Much of this debate probably reflects our poor state of scientific knowledge (Dayton et al. 2000, Ardron 2008), given that few specific predictions can be made confidently regarding ecological changes associated with declaration of new MPAs.

Uncertainty as to the overall ecological value of MPAs can be attributed to several factors: (1) field investigations in the marine environment are logisti- cally difficult and expensive, and hence are rarely attempted at large scales (Jennings et al. 2008, Richardson \& Poloczanska 2008); (2) studies undertaken at small scales $(<10 \mathrm{~km})$ possess little generality because results can be affected by idiosyncratic local conditions (Wiens 1989, Halford \& Perret 2009); (3) modelling studies lack a broad empirical basis and deal with the huge number of species and linkages in natural systems through aggregation of variables or regarding them as constant (Wolff 2002, Werner et al. 2007, Codling 2008); (4) many of the more important ecological processes (e.g. larval dispersal, predation of mobile animals) are not readily amenable to observation or experimentation (Cowen et al. 2007, Botsford et al. 2009); and (5) complex nonlinearities and inter- 
actions between ecological and environmental factors are pervasive (Shears \& Babcock 2002, Willis et al. 2003, Edgar et al. 2007, Guidetti \& Sala 2007, McClanahan 2008).

Outcomes of MPA studies are also potentially confounded by a large suite of extrinsic factors, as summarised in Table 1, which can potentially affect responses of flora and fauna within protected zones. In order to rigorously assess the varying contributions of these different factors, extremely large data sets are required. In particular, a reasonable understanding of how aspects of MPA design affect conservation outcomes requires analysis of numerous MPAs given that each MPA, or individual zoned area within a MPA, should be regarded as a single independent replicate.

Because of the difficulty in collecting standardised data over large geographic distances, field investigations rarely encompass multiple MPAs. While some have focused on regional scales (notably Wantiez et al. 1997, Edgar \& Barrett 1999, Tetreault \& Ambrose 2007, Harmelin-Vivien et al. 2008), very few have approached the continental scale (Newman et al. 2006, Mora 2008, Russ et al. 2008, Sweatman 2008). Consequently, broad-scale analyses of MPA effects have primarily been attempted using meta-analysis, where summary statistics are compiled from published studies reported by different investigators.
Meta-analyses suffer, however, from biases associated with their underlying sets of publications. The process of scientific publication selects for studies showing significant outcomes (Kotiaho \& Tomkins 2002, Tomkins \& Kotiaho 2004), potentially biasing any overall evaluation of MPA effects because species or locations generating non-significant effects are largely excluded.

Clearly, broad-scale analyses based on standardised data sets should generate more accurate assessments of MPA efficacy and better predictive capacity than meta-analyses, providing that standardised data are available in sufficient quantity and with appropriate quality and geographic span. In the present study, field survey data obtained at the continental scale are used to quantify differences between MPAs and adjacent fished reference zones across Australia with respect to the species richness and density of fishes and invertebrates, and biomass of fishes. Geographic scale limitations were overcome through the assistance of volunteer divers involved in the Reef Life Survey program (www.reeflifesurvey.com).

Reef Life Survey differs from most other volunteer diver programs in targeting and supporting only the most skilled subset of the recreational diving community. A small group of committed recreational divers are trained in the technical skills needed to scientifi-

Table 1. Factors affecting the outcomes of MPA investigations

\section{Site-related effects}

(1) Regional biogeographic influences, including tropical, temperate or polar location (Bellwood et al. 2004, Russ et al. 2008)

(2) Local environmental influences, including currents, habitat type and physical structure-many low profile reefs, for example, possess few structural refuges and consequently have little capacity to accommodate large fishes or rock lobsters even if fully protected from fishing (Russ 2002, Guidetti \& Sala 2007, Eggleston \& Parsons 2008)

(3) Distance from protected area boundary, which is associated with magnitude of spillover (Francini-Filho \& Moura 2008, Harmelin-Vivien et al. 2008)

(4) Time since MPA declaration (Guidetti \& Sala 2007, Claudet et al. 2008, Edgar et al. in press)

\section{Taxonomic effects}

(1) Species or component of biodiversity of interest—different species respond very differently to MPA protection, depending in part on life history traits such as size and rates of dispersal, with either positive or negative population changes possible as a result of differential exploitation and trophic interactions (Barrett et al. 2007, Guidetti \& Sala 2007, Tetreault \& Ambrose 2007, Preuss et al. 2009)

\section{Management effects}

(1) Pre-existing fishing effort, which affects the extent to which a site can potentially recover after fishing ceases (Lynch 2006)

(2) Level of compliance of laws and regulations, and legal enforcement capacity (Kritzer 2004, Little et al. 2005, Byers \& Noonburg 2007, Guidetti et al. 2008, Sethi \& Hilborn 2008)

(3) Management regulations, including whether fully or partially protected from fishing (Williams et al. 2006, Lester \& Halpern 2008)

(4) Level of resource extraction of surrounding areas, which can affect spillover, and also affects changes at sites used as references for changes within MPAs (Côté et al. 2001, Eggleston \& Parsons 2008)

\section{MPA design effects}

(1) Size of MPA (Kritzer 2004, Claudet et al. 2008)

(2) Source/sink dynamics associated with currents and proximity to adjacent MPAs (Crowder et al. 2000, Carr et al. 2003)

(3) Porosity of protected area boundaries for species of interest, particularly whether preferred habitat extends continuously across boundary (Forcada et al. 2008) 
cally survey marine communities. The project is based on the premises that: (1) when appropriately trained and resourced, the most enthusiastic and knowledgeable recreational divers can undertake routine investigation of the marine environment to a level equivalent to a professional scientific diver; and (2) a large proportion of the best recreational divers are willing to assist scientific studies, and will maintain long-term enthusiasm, if provided appropriate feedback, recognition and support to cover some costs of field activities.

\section{MATERIALS AND METHODS}

Study sites. Field surveys, some involving diver training courses, were undertaken at 8 temperate and 3 subtropical Australian MPAs distributed around $5000 \mathrm{~km}$ of coast from northern New South Wales (NSW) to central Western Australia, and eastern Tasmania (Fig. 1). Within each MPA, numerous transect blocks were surveyed at sites inside sanctuary zones (SZs) protected from fishing and also adjacent fished zones (FZs) that either lay outside the MPA or were designated as general use zones within the larger multi-zoned MPAs. The exception was Solitary Islands Marine Park, where $11 \mathrm{SZs}$ were investigated but no FZs.

A total of 131 sites were investigated during the present study, comprising 65 sites in SZs and 66 in FZs (Fig. 1). Data at each site were collected along multiple transect blocks haphazardly distributed by divers adjacent to the georeferenced boat mooring. A total of 577

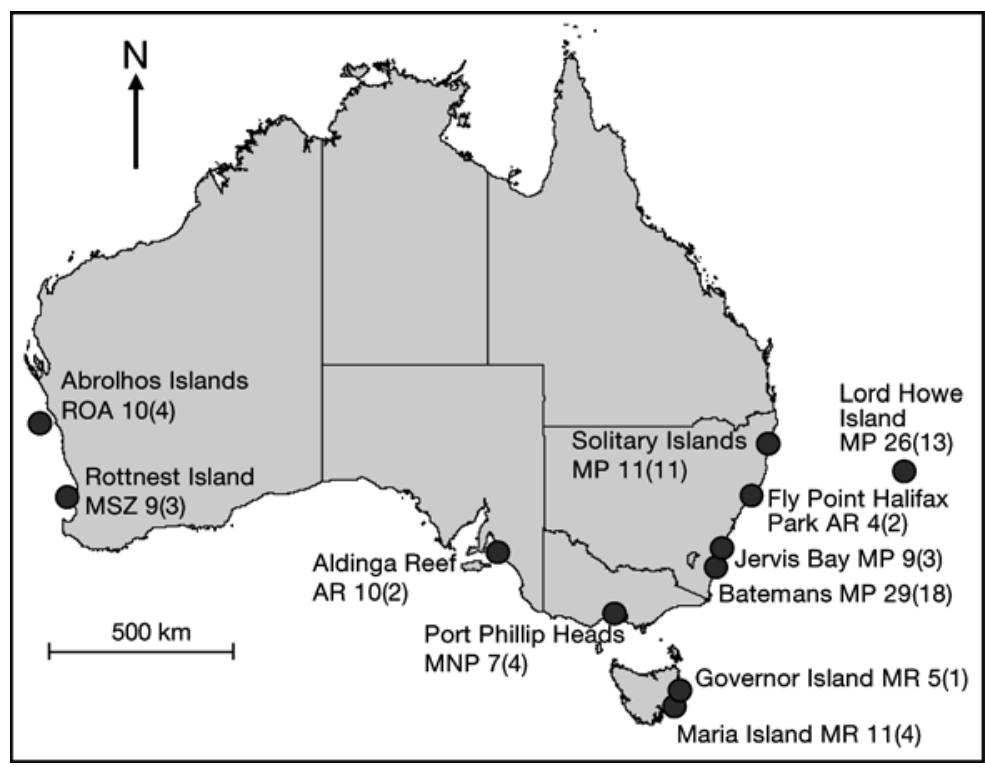

Fig. 1. MPAs with reef sites surveyed by volunteer divers. Number of sites surveyed in each MPA is shown with number of sanctuary zone sites in parentheses. AR: Aquatic Reserve, MNP: Marine National Park, MP: Marine Park, MR: Marine Reserve, MSZ: Marine Sanctuary Zones, ROA: Reef Observation Areas transect blocks were censused between January and September 2008, representing an average of 4.4 transect blocks per site. Surveys at each MPA were temporally interspersed in FZs and SZs within survey periods of 2 to $15 \mathrm{~d}$.

Underwater visual censuses. Volunteer divers were trained in visual census methods that are slightly simplified in relation to, but that generate data directly comparable with, methods applied in long-term scientific monitoring programs across southern Australia (Edgar \& Barrett 1999, Edgar et al. 1997). Densities of fishes and macroinvertebrates were separately estimated along $50 \mathrm{~m}$ transect lines set along a depth contour.

The fish censusing protocol at each site involved a diver tying the end of a $50 \mathrm{~m}$ transect line to the reef then swimming along the depth contour while recording the number, estimated size category and species of all fishes sighted within $2.5 \mathrm{~m}$ of either side of the diver. The transect block thus encompassed a total reef area of $50 \times 5 \mathrm{~m}$. A second diver, or the first diver on return, also censused an adjacent replicate block by swimming parallel to, but not overlapping, the initial transect. Data were recorded on waterproof paper. Size classes of fish used in the present study were 25, $50,75,100,125,150,200,250,300,350,400$ and 500 $\mathrm{mm}$ total length. Lengths of the few fish larger than $500 \mathrm{~mm}$ sighted were individually estimated to the nearest $125 \mathrm{~mm}$. Abundances of fishes in large schools were estimated by counting a subset of ca. 20 individuals and estimating the percentage of the total school that the subset comprised.

Mobile macroinvertebrates were surveyed in two $1 \mathrm{~m}$ wide blocks on either side of the same transect lines as used for fish counts (total area surveyed $=50 \times 2 \mathrm{~m}$ ). The algal canopy was brushed aside where necessary to search all exposed surfaces of the substratum for large mobile invertebrates (echinoderms, large gastropods and large crustaceans), with abundance and species recorded. Transect line depths varied between 2.5 and $20 \mathrm{~m}$, with most transects set between 5 and $10 \mathrm{~m}$ depth.

Analyses of data quality. The quality of survey data collected by volunteers was assessed using data from the first 4 Reef Life Survey training courses, which were held at Flinders Island, Tasmania (28 Jan to $1 \mathrm{Feb}$ 2008), Second Valley, South Australia (5 to 10 Feb 2008), Jervis Bay, NSW (18 to 22 Feb 2008), and the Abrolhos Islands, Western Australia (21 to 25 March 2008). During training dives, experienced scientific divers undertook surveys along the same or adjacent lines to those set by volunteer divers, 
allowing comparison of volunteer data with those of scientists at the same time and place. Scientists also assessed the correct application of survey methods by volunteers and provided feedback for improvement. At least 2 scientists collected data with volunteers at each site used for training.

Data collected by volunteers were analysed for their similarity to survey information collected by experienced scientific divers (hereafter referred to as the 'trainers') at the same reef sites at the same time. Multivariate similarity includes information on both species composition and density or biomass estimates of individual species, and thus is regarded as an appropriate measure of whether volunteers were collecting data similar to those of trainers in both aspects.

Bray-Curtis similarity indices (see Faith et al. 1987) relating trainee and trainer data were calculated for each diver at each site using $\log (\mathrm{x}+1)$-transformed data for all fish and macroinvertebrate species observed. Whilst abundance data were used for macroinvertebrates, biomass estimates were used for fish data (see below for details of biomass estimation) because most analyses involving fishes were based on biomass data. Biomass estimates also take into account the estimates of fish sizes, and thus similarities based on these allow a more thorough assessment of the quality of fish data collected by volunteers. An index of similarity (IS), which relates the similarity of volunteers to trainers with the similarity of one trainer to another at the same site, was calculated using the formula:

$$
I S_{i 1}=\frac{S_{i 1} v t}{S_{1} t t}
$$

where $S_{i 1} v t$ is the Bray-Curtis similarity of volunteer diver $i$ to the trainer in closest proximity on dive 1, and $S_{1} t t$ is the Bray-Curtis similarity between 2 trainers also at that site.

The IS accounted for the variation in similarities between sites caused by local habitat heterogeneity, but was still subject to variation arising as a consequence of any differences in community type censused on the different transect lines set by the 2 trainers. Regressions of the mean (ordinary least squares) and of the 10th percentile (quantile regression) were performed on the IS to establish the existence and nature of relationships with the number of training dives undertaken. The regression of the 10th percentile (Cade \& Noon 2003) assessed whether the poorest quality survey estimates at a site improved with training.

Data produced by volunteers that lay within $10 \%$ of the mean similarity of data produced by the 2 trainers (i.e. with an IS $>0.9$ ) was considered to be of adequate standard. For analysis of MPA effects, as described below, no data produced during the first 6 training dives undertaken by each volunteer diver were used.
Fish data produced by volunteers after this time were used if the trainee had achieved the threshold for data quality over the 3 subsequent dives (i.e. their mean IS was $>0.9$ over training dives 7,8 and 9). A total of $15 \%$ of trained divers failed to achieve this benchmark, hence their data were not used further.

The quality of data produced by trained volunteers was additionally assessed against data produced by scientists following joint data-gathering surveys at 61 sites in 5 regions (Batemans Bay, Lord Howe Island, Port Phillip Bay, Rottnest Island and Maria Island). Components of variance associated with differences between volunteer and trainer data sets were estimated using a mixed-model ANOVA design for 6 important univariate metrics: total number of fish species, estimated fish biomass, total abundance of fishes, mean size of fish sighted, total number of macroinvertebrate species and total abundance of macroinvertebrates per transect block. Biomass and abundance data were square-root transformed to avoid heteroscedasticity.

Factors included in the ANOVA model were region (locations with 7 to 27 sites nested within, extending over ca. $10 \mathrm{~km}$ ), site (locations with 2 to 10 transect blocks nested within, extending over ca. $200 \mathrm{~m}$ ), diver experience (2 levels, volunteers and trainers) and diver (5 trainers and 12 volunteers, nested within experience). Experience comprised a fixed factor while the other factors were considered random.

Components of variance were calculated using PERMANOVA, a multivariate permutational procedure that also calculates true components of variance when transect data are grouped using Euclidean distance for a single variable (Anderson et al. 2008). PERMANOVA was also used to estimate components of variance for the multispecific fish and invertebrate community data sets. In the community analyses, similarity matrices for fish biomass and invertebrate abundance (both square-root transformed) were calculated using the Bray-Curtis index (Anderson 2001). For ease of calculation, the fish data set was reduced by excluding species sighted on only 1 or 2 transects (194 fish species included in analysis) while invertebrate species present on a single transect were also excluded (109 species analysed).

Continental-scale analysis of MPA effects. Data collected by trained volunteers and scientific trainers at 11 MPA locations around southern Australia were analysed to examine broad-scale effects of protection from fishing on reef fish and macroinvertebrate communities. FZ sites comprised those within MPA boundaries that were in areas with fishing permitted, or nearby sites outside MPA boundaries. SZ sites were all located in 'no-take' areas protected from all forms of fishing. 
A mixed model ANOVA design was used to assess, for fish and invertebrate community metrics, the effects of region (4 levels: sites in or near MPAs in NSW, Tasmania, southern Australia [Victoria/SA] and Western Australia [WA]), MPA location (11 levels: MPAs nested within region) and protection status (2 levels: fished zones and sanctuary zones). Data were subdivided into regions using political boundaries primarily so that outcomes could be applied within separate management processes in different states. These boundaries also corresponded with major biogeographical disjunctions (Bennett \& Pope 1960, Interim Marine and Coastal Regionalisation for Australia Technical Group 1998).

In analyses, location was regarded as a random factor, status a fixed factor and region also considered a fixed factor because all major temperate Australian regions were included in analyses. Calculations were performed using PERMANOVA, with data from the location $\times$ status interaction pooled with the error term when $\mathrm{p}$-values associated with F-tests exceeded 0.25, as recommended by Winer et al. (1991).

Metrics included in analyses were total density of fishes, density of fishes $>30 \mathrm{~cm}$ (total length), density of fishes $\leq 30 \mathrm{~cm}$ (total length), total biomass of fishes, the biomass of fishes $>30 \mathrm{~cm}$, biomass of fishes $\leq 30 \mathrm{~cm}$, fish species richness (no. of species per transect block), invertebrate species richness, total density of invertebrates and total density of sea urchins. Density of sea urchins was included because of the possibility that trophic cascades in SZs caused increased numbers of large urchin predators that in turn resulted in reduction in urchin numbers (Shears \& Babcock 2003, Pederson \& Johnson 2006). All metrics examined other than those for species richness were $\log _{10}$-transformed before analysis. Plotted figures are based on nontransformed data.

Fish abundance counts and size estimates were converted to biomass estimates using length-weight relationships presented for each species (in some cases genus and family) in Fishbase (www.fishbase.org). In cases where length-weight relationships were described in Fishbase in terms of standard length or fork length rather than total length, additional equations provided in Fishbase allowed conversion to total length, as estimated by divers. For improved accuracy in biomass assessments, the bias in divers' perception of fish size underwater was additionally corrected using relationships presented in Edgar et al. (2004). Note that estimates of fish abundance made by divers can be greatly affected by fish behaviour for many species (Edgar et al. 2004); consequently, biomass determinations, like abundance estimates, can reliably be compared only in a relative sense (i.e. for comparisons with data collected using the same methods) rather than providing an accurate absolute estimate of fish biomass for a patch of reef.

\section{RESULTS}

\section{Analysis of data quality}

Whilst some scatter was evident in multivariate similarities in volunteer training data, most communitylevel estimates by volunteer divers of fish biomass and invertebrate densities were comparable to data produced by trainers at the same site (Fig. 2), including estimates made by some volunteers during their first training survey. Significant relationships were found between the IS and number of surveys completed for both fishes $(\mathrm{p}<0.001)$ and macroinvertebrates $(\mathrm{p}<$ 0.001), indicating a general trend for improvement in data quality during training.

Regression of the 10th percentile of similarity data with the number of training dives was also significant for both fishes $(\mathrm{p}=0.037)$ and macroinvertebrates $(\mathrm{p}=$ 0.005). This suggests that in addition to a relatively high average similarity throughout and a general trend for improvement, the frequency of poor quality data (i.e. data least similar to those of scientists) also decreased during training dives.

After completion of training, data produced by volunteers, as assessed by mixed model PERMANOVA using Euclidean distance to calculate similarity, was indistinguishable from data produced by the 5 trainers associated with the Reef Life Survey program. The factor dive experience was not significant in any test of univariate fish and invertebrate metrics, nor for multivariate analyses of community structure (Table 2). In fact, experience explained $<1 \%$ of total variance in all models other than for fish biomass, where it explained $5 \%$ of the total variance.

Variability in data produced by different divers at each site was also relatively low, as indicated by the relatively low proportion of total variance explained by the factor diver. This factor includes variation between transects within a site, which includes both spatial variation in faunal communities within sites and also individual biases associated with counts by different divers. These 2 elements could not be separated because divers surveyed separate transects within sites.

Amongst the metrics examined, variability between individual divers appeared to be highest for fish size estimates, as $17 \%$ of total estimated variance in mean fish size was contributed by the factor diver. This factor additionally contributed $13 \%$ of total variance for invertebrate species richness, and was also significant for all other metrics. For other univariate metrics, diver contributed approximately $5 \%$ of the total variance, 


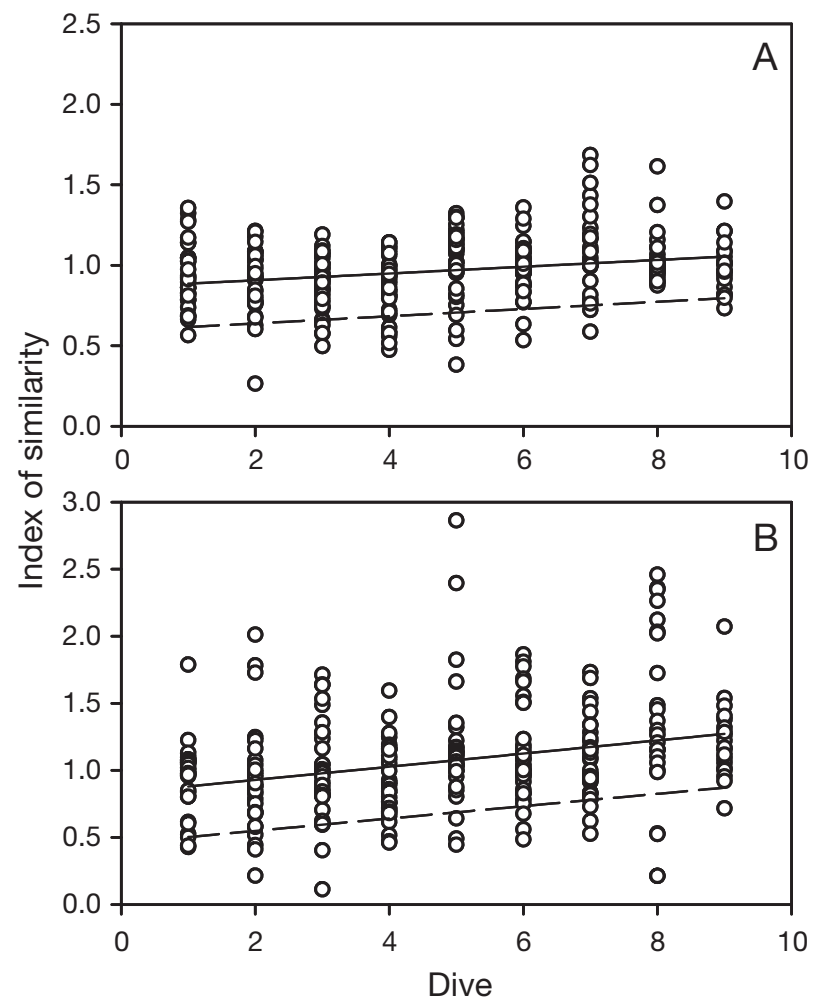

Fig. 2. Improvement in the quality of volunteer diver data (index of similarity, IS) with the number of training dives. IS relates the multivariate similarities of data from volunteers and trainers to those between trainers at each site, based on (A) fish biomass and (B) macroinvertebrate abundance data. The solid lines are significant linear regressions (fishes: IS = $0.865+0.021 \times$ (no. training dives), $\mathrm{p}<0.001$; macroinvertebrates: IS $=0.831+0.049 \times$ (no. training dives), $p<$ 0.001 ); dashed lines are significant regressions of the 10th percentile of the data (fishes: intercept $=0.595$, slope $=0.022$, $\mathrm{p}=0.037$; macroinvertebrates: intercept $=0.457$, slope $=0.046$, $\mathrm{p}=0.005)$

and about $2 \%$ to the fish and invertebrate community level data sets.

Regional influences across the continent contributed most of the estimated variance for fish species richness
( $50 \%$ of total estimated variance), fish biomass (38\%), fish abundance $(41 \%)$, invertebrate abundance $(47 \%)$, fish community patterns (41\%) and invertebrate community patterns $(43 \%)$, whereas variation between transects contributed most to variation in mean fish size $(36 \%)$, and variation between sites contributed most to variation in invertebrate species richness (44\% of total). Variation between sites was highly significant for all metrics and contributed between 17 and $36 \%$ of variation in the various models examined.

With respect to commitment, volunteers who collected the best quality data during training tended to persist with the Reef Life Survey program and dedicate the greatest amount of time to follow-up surveys. This is indicated by the significant positive relationship (Pearson correlation coefficient $=0.465, \mathrm{p}=0.010$ ) evident between the average quality of data (i.e. similarity to data of trainers) after 6 dives during the training courses and number of full surveys completed subsequent to training (Fig. 3).

The best $27 \%$ of divers at the end of the initial 4 training courses all continued collecting data in their free time (see Fig. 3), and none of the least competent $21 \%$ have done more than 2 surveys post-training. Out of the $15 \%$ of divers whose data fell below the similarity cut-off for reasonable quality during training dives, only one has continued collecting data. This diver has since gained more experience and has participated in an additional training trip, and now appears to be collecting useable data. Thus, all data collected by volunteers post-training was considered suitable for scientific analysis.

\section{MPA effects}

Mixed model PERMANOVAs indicated that density of large $(>30 \mathrm{~cm})$ fishes, total fish biomass and biomass of large fishes all varied significantly with MPA protection status, while total fish density and small fish den-

Table 2. Estimates of components of variance derived by PERMANOVA for different univariate metrics and for site similarity matrices calculated using square-root transformed fish biomass and invertebrate abundance data. Degrees of freedom for the investigated factors region, site (nested within region), experience, diver (nested within experience) and error are 4, 50, 1, 16 and 271, respectively. Significance of factors is indicated by outcomes of PERMANOVA pseudo F-tests; ${ }^{* * *} \mathrm{p}<0.001$

\begin{tabular}{|c|c|c|c|c|c|c|c|c|}
\hline \multirow[t]{2}{*}{ Factor } & \multirow{2}{*}{ Species } & \multirow{2}{*}{$\overline{\text { Biomass }}$} & \multicolumn{2}{|c|}{ Fish } & \multicolumn{2}{|c|}{ — Invertebrate — } & \multirow{2}{*}{$\begin{array}{c}\text { Fish } \\
\text { community } \\
\text { biomass }\end{array}$} & \multirow{2}{*}{$\begin{array}{c}\text { Invertebrate } \\
\text { community } \\
\text { density }\end{array}$} \\
\hline & & & Number & Mean size & Species & Number & & \\
\hline Region & $25.8^{* * *}$ & $0.87^{* * *}$ & $0.95^{* * *}$ & $9.0^{* * *}$ & 1.18 & $1.11^{* * *}$ & $1954^{* * *}$ & $1844^{* * *}$ \\
\hline Site(Region) & $9.2^{* * *}$ & $0.43^{* * *}$ & $0.83^{* * *}$ & $6.0^{* * *}$ & $7.31^{* * *}$ & $1.05^{* * *}$ & $922^{* * *}$ & $1151^{* * *}$ \\
\hline Experience & 0 & 0.12 & 0 & 0.2 & 0 & 0 & 19 & 6 \\
\hline Diver(Experience) & $1.9^{* * *}$ & $0.19^{* * *}$ & $0.08^{* * *}$ & $5.5^{* * *}$ & $2.12^{* * *}$ & $0.06^{* * *}$ & $152^{* * *}$ & $64^{* * *}$ \\
\hline Error & 15.0 & 0.79 & 0.48 & 11.7 & 5.86 & 0.45 & 1718 & 1243 \\
\hline Total & 51.9 & 2.40 & 2.33 & 32.3 & 16.47 & 2.67 & 4765 & 4307 \\
\hline
\end{tabular}




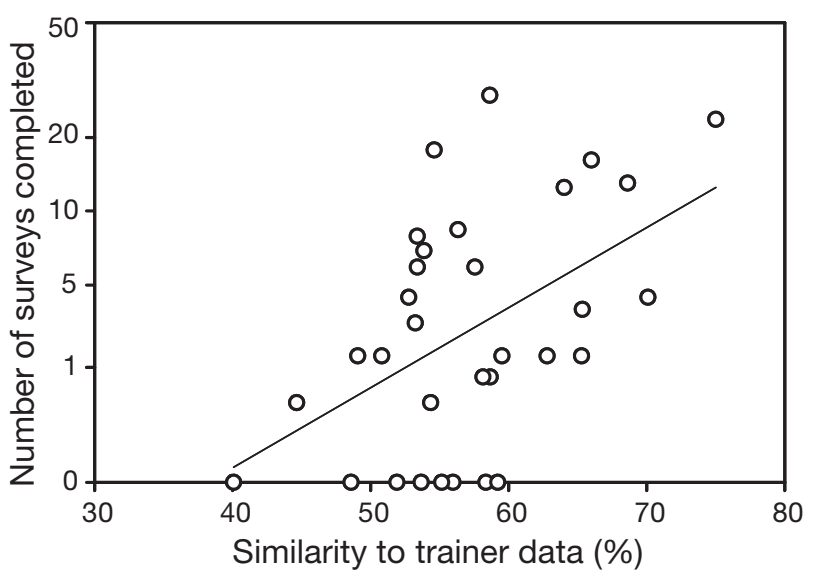

Fig. 3. Relationship between number of full surveys completed by each volunteer diver since training and mean BrayCurtis similarity of volunteer and trainer survey data sets after 6 training dives. The solid black line represents a significant linear regression: $\log ($ no. surveys +1$)=-18.98+0.422 \times$ similarity of fish data, $\mathrm{p}=0.010$

sity showed non-significant relationships (Table 3). Fish biomass was consistently higher in SZs in all regions, with ca. $10 \mathrm{~kg}$ higher biomass per transect block than in FZs (Fig. 4). For the 18 tests involving effects of MPA status (including interaction) on density and biomass described in Table 3, 5 tests produced significant outcomes, a much greater number than the 0.9 Type I errors predicted for 18 separate tests at $\alpha=0.05$.

Fish species richness exhibited variable relationships between SZs and FZs in different MPAs, with a significant interaction produced using PERMANOVA. Overall, this metric appeared slightly elevated in SZs relative to FZs in the Tasmania, NSW and Victoria/SA regions (Fig. 5). Invertebrate species richness and abundance were both significantly lower in SZs than FZs (Table 3). In MPAs in the Tasmania and Victoria/ SA regions, invertebrate species richness tended to be depressed in SZs relative to FZs, whereas in some NSW MPAs the opposite trend occurred (Fig. 5). Neither macroinvertebrate nor sea urchin density varied consistently between SZs relative to FZs in plots with untransformed data (Fig. 6).

The various PERMANOVA tests also indicated that mean values for most of the fish and invertebrate metrics examined varied significantly between different regions or locations (Table 3). Nevertheless, patterns of density and biomass of fishes $>30 \mathrm{~cm}$ were consistent across the continental range of the present study.

Relationships between MPA effects and fish size were assessed by relating mean fish density per transect block at different sites with size classes of fishes in well-established MPAs (i.e. those declared for more than 5 yr, Edgar et al. in press). Size class information

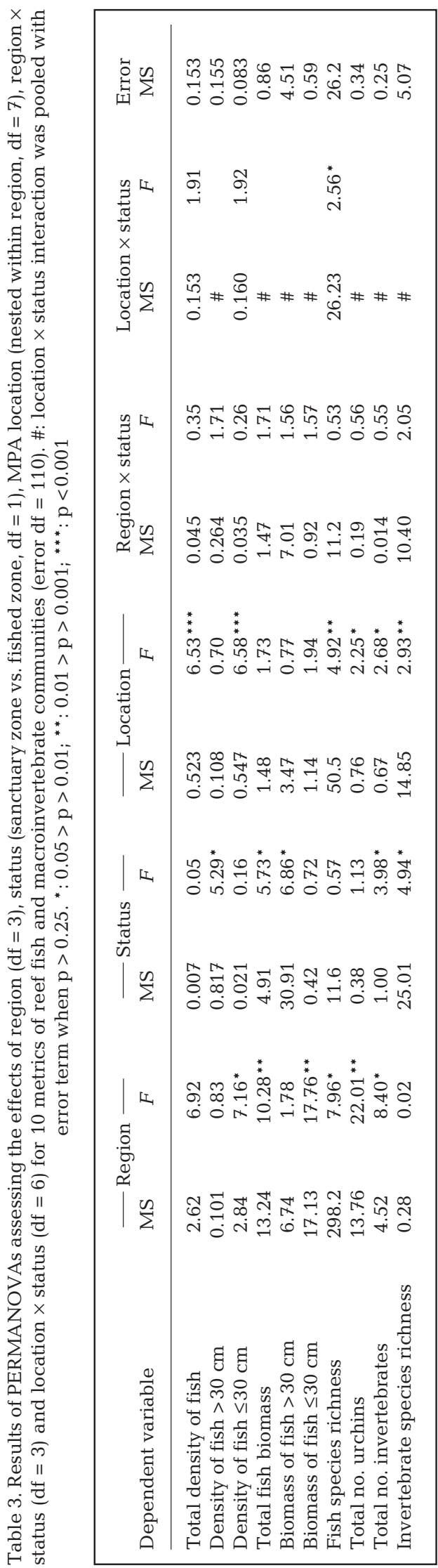



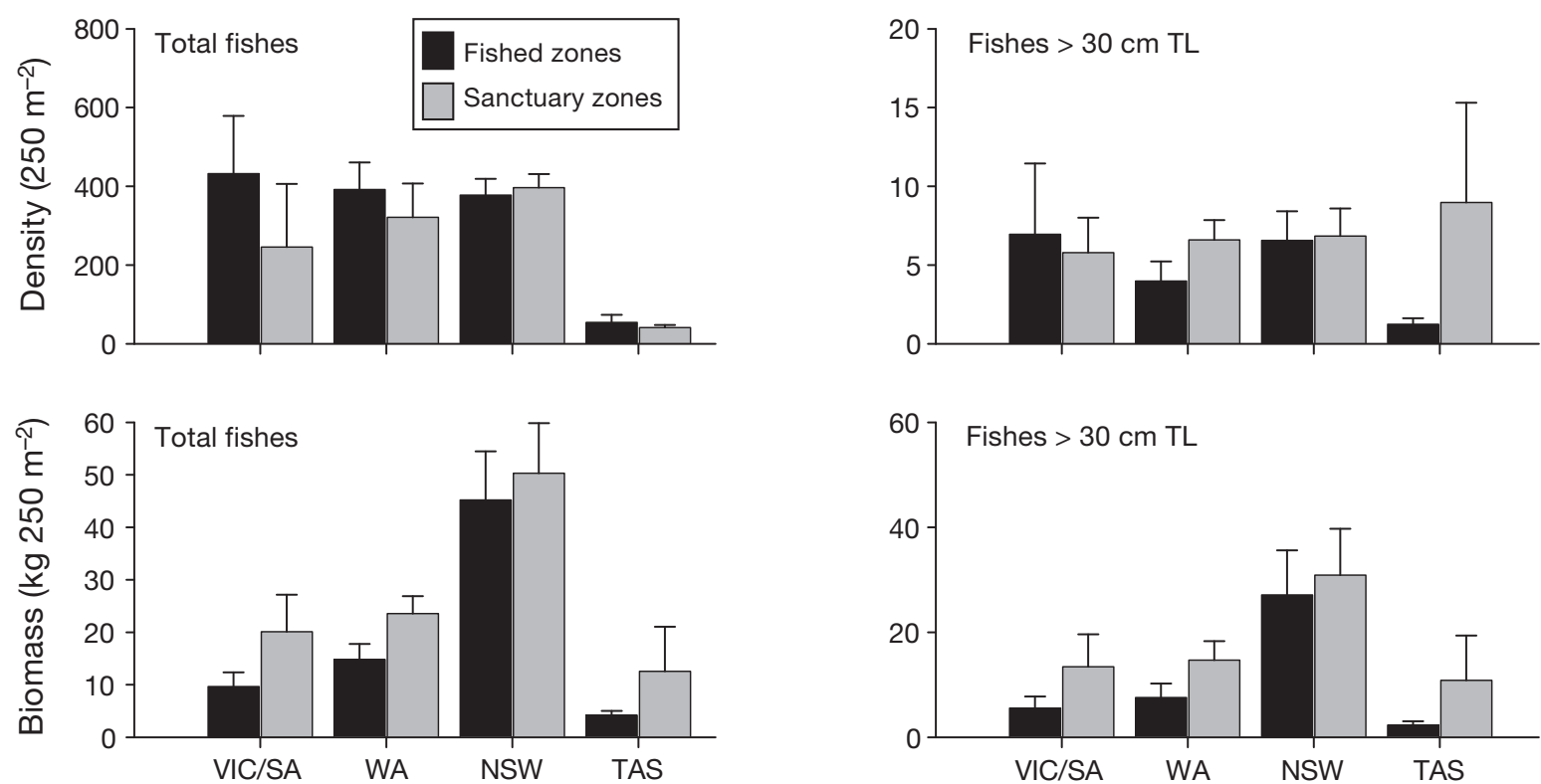

Fig. 4. Mean density and biomass of fishes (+SE) per transect block in different regions. VIC/SA: Victoria/South Australia; WA: Western Australia; NSW: New South Wales; TAS: Tasmania. TL: total length

was binned into $2.5,5,10,20,40$ and $\geq 80 \mathrm{~cm}$ size classes (Fig. 7). Fishes in the smallest $(2.5 \mathrm{~cm})$ size class were on average approximately 4 times more abundant in FZs than in SZs (Fig. 7). Although this difference appears highly significant in the figure, and a significant result is evident in a $t$-test with nontransformed data $(p=0.027)$, the test was influenced
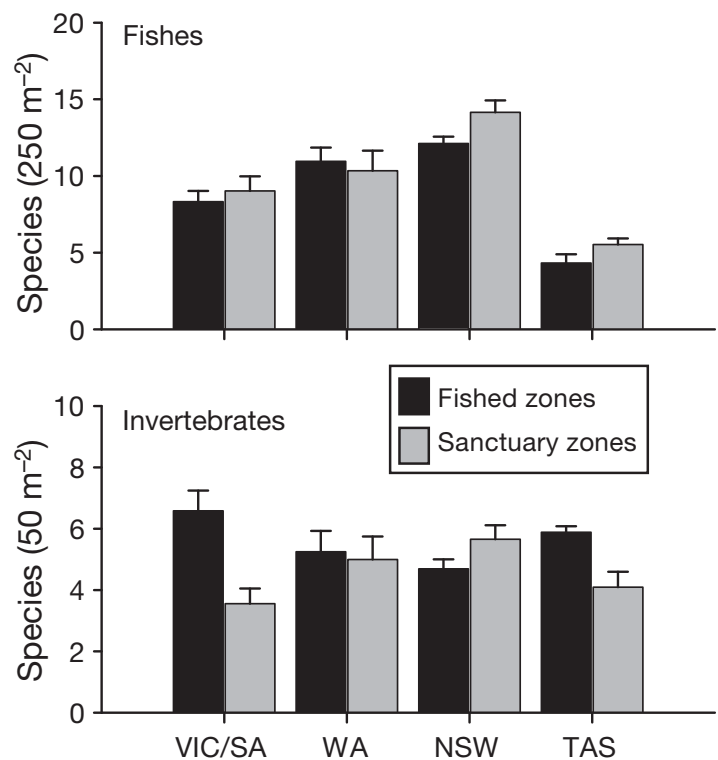

Fig. 5. Mean number (+SE) of fish and mobile macroinvertebrate species per transect block in different regions. See Fig. 4 for region abbreviations by a few sites with very high abundances of small fishes; when assessed using $t$-test with log-transformed data the result was only significant if $\alpha$ is set at $0.1(p=0.091)$. By contrast, the largest $(\geq 80 \mathrm{~cm})$ fishes observed were an order of magnitude more often sighted in SZs than FZs, a highly significant outcome $(\mathrm{p}=0.009)$.
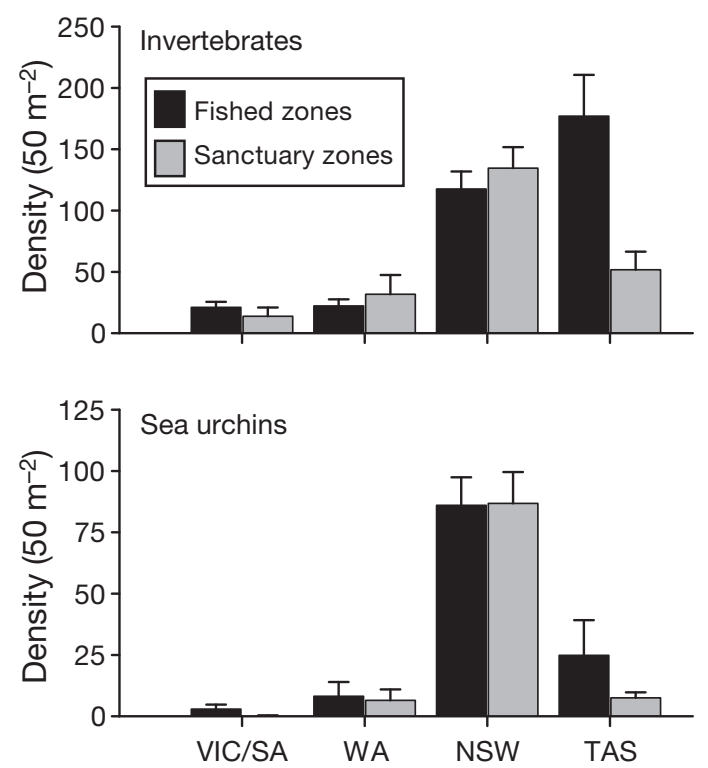

Fig. 6. Mean density (+SE) of mobile macroinvertebrates and sea urchins per transect block in different regions. See Fig. 4 for region abbreviations 


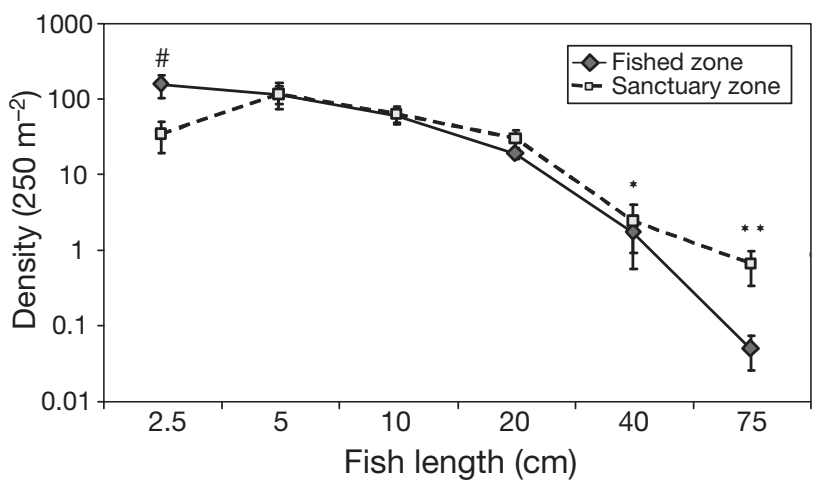

Fig. 7. Relationship between mean fish density per transect block ( \pm SE of site means) in different size classes in sanctuary zones and fished zones. Size classes with significant differences in densities between management zone types, as revealed using $t$-tests with log-transformed data, are indicated by asterisks. \#: $0.1>\mathrm{p}>0.05{ }^{*}{ }^{*}: 0.05>\mathrm{p}>0.01{ }^{* * *}$ : $0.01>$ $\mathrm{p}>0.001$. Data relate to MPAs established $>5 \mathrm{yr}$

\section{DISCUSSION}

\section{MPA effects}

Studies of ecological changes that follow the establishment of MPAs comprise broad-scale manipulative experiments into effects of fishing, with human predators excluded from defined patches of coast (Walters \& Holling 1990, Micheli et al. 2004). Two expected results of such studies are higher numbers of large fishes and greater fish biomass in SZs than in FZs. These outcomes were evident in our analyses and have also been widely reported in previous MPA studies (Russ 2002, Edgar et al. 2007, Harmelin-Vivien et al. 2008, Kleczkowski et al. 2008), including meta-analyses (Côté et al. 2001, Halpern 2003). In the case of total animal density and species richness metrics, however, differences were apparent between our results and outcomes of published meta-analyses.

Amongst the density and species richness metrics examined, number and species richness of invertebrates both declined in MPAs, while fish species richness showed a variable response in different MPAs. The lack of a positive response to SZs for fish density, and reduced species richness and densities of invertebrates, contrasts with outcomes reported elsewhere (Mosquera et al. 2000, Côté et al. 2001, Halpern \& Warner 2002, Halpern 2003). For example, Halpern (2003) found that fishes and invertebrates in 63\% of reserves in a global meta-analysis had significantly higher densities than in fished areas ( $p \ll 0.001)$, and $59 \%$ of reserves had significantly higher species richness than fished areas ( $\mathrm{p} \ll 0.001$ ).

The difference in outcomes between the present empirical study and previous meta-analyses probably relates in part to publication selectivity. Large fishes as a group, including the commercially important species, were found in the present study to be significantly more abundant in SZs than FZs, but when total fish as a group were considered this trend was swamped by the variability in patterns displayed by the much more abundant smaller fishes. The published literature is dominated by studies of large commercial species; hence it is not surprising that meta-analyses show extremely strong overall positive relationships between fish density and MPAs.

The present study in fact indicated that many invertebrates and small fishes decline in numbers in MPAs. Total invertebrate numbers were significantly lower in SZs than FZs (Table 3). A steep decline in fish density in the $2.5 \mathrm{~cm}$ relative to $5 \mathrm{~cm}$ size class was also observed in SZs but not in FZs (Fig. 7). The $t$-test associated with this difference was at the margins of statistical significance, depending on transformation, hence further data are required to better understand this relationship.

A reduced density of small fishes and invertebrates in SZs is consistent with the hypothesis that trophic cascades occur in protected MPAs. If this hypothesis is correct, then increased densities of large fish predators following protection from fishing will affect prey populations. Fish predators typically consume prey at ca. $5 \%$ of their body length (Edgar \& Shaw 1995), hence increased densities of fishes in the 40 to $100 \mathrm{~cm}$ size range would be expected to have the greatest impact on prey animals (fishes and invertebrates) in the 1.5 to $5 \mathrm{~cm}$ size range. An alternate hypothesis for low densities of small fish in SZs is that small animals adapted behaviourally to the presence of large fish predators by hiding (Milazzo et al. 2005), so were not as readily observed by divers in SZs.

Although invertebrate species richness has been cited as generally higher in SZs than in FZs (Halpern 2003), no convincing explanation accounts for this pattern at the local scale. Because of increased fish and lobster predation in SZs, decreased richness of invertebrates along transects could be expected in MPAs, and was in fact found in the present study. We attribute significantly lower invertebrate species richness in SZs and a decreased likelihood of observing the rarer invertebrate species on each transect in SZs to impacts of predators on invertebrate numbers. A decline in invertebrate species richness associated with declining invertebrate populations was directly observed during $10 \mathrm{yr}$ of ecological monitoring following establishment of the Maria Island MPA (Barrett et al. 2009).

By contrast, fish species richness at the scale of transects was higher in many SZs than adjacent FZs, albeit with significant variation between different MPAs. The presence of elevated numbers of large exploited fishes 
in SZs presumably increased the likelihood of sighting such species along individual transects in MPAs.

Regardless of patterns of species richness at the scale of transects, MPAs increase biodiversity at regional scales through the addition of unexploited community types to the seascape. MPAs protected from fishing long-term possess community types quite different from fished areas in terms of total fish biomass (Edgar et al. in press), and include over an order of magnitude more very large ( $\geq 80 \mathrm{~cm}$ size class) fishes.

The age of MPAs possibly confounded our PERMANOVA tests because of systematic variation in this important factor between regions (Edgar et al. in press), with most SZ sites studied in NSW, in particular, protected recently $(<5 \mathrm{yr})$ compared to SZ sites investigated in other states. Like most published ecological studies of MPA effects, results of the present study were also potentially confounded by spatial differences between SZ and FZ sites that existed prior to declaration of the various MPAs (see Willis et al. 2003).

Thus, conclusions would have been strengthened if time series data had been available for before-after control-impact (BACI) type analyses (Green 1979), rather than the control-impact analyses undertaken here. Regardless, we do not consider that this potential source of error greatly affected conclusions because of the large number of MPAs investigated, and hence the low probability that idiosyncratic regional biases inside versus outside MPAs affected general outcomes. Moreover, while biomass of fishes $>30 \mathrm{~cm}$ was significantly higher in SZs relative to FZs, the densities of fishes $\leq 30 \mathrm{~cm}$ did not significantly differ between SZs and FZs, an indication that the non-exploited component of the fish communities were broadly similar in the 2 zone types (Tetreault \& Ambrose 2007).

\section{Contribution of volunteer divers to ecological monitoring}

The quality of data produced by volunteer divers who participated in this project was comparable to data recorded by experienced scientific divers. No significant differences between data produced by volunteers and professionals were evident for any of the community metrics examined, including estimates of numbers of species per transect, total faunal densities of animals per transect and mean size of fishes (Table 2). The close similarity in assessments of species composition between volunteers and experienced scientists additionally indicates that volunteers are adept at species-level field identifications of both fishes and invertebrates.
Analysis of estimated components of variance not only indicated that the level of experience contributed negligibly to total variation between transects, but also that variation in data produced by individual divers was also much lower than variance generated by differences between replicates within sites and variance between sites within regions. For all metrics investigated other than number of invertebrate species per transect, between-diver variance was also much lower than variation between regions. Thus, for broad-scale tests, variation between divers contributed little additional statistical noise. While data produced during underwater visual censuses undoubtedly possess substantial biases (Edgar et al. 2004), such biases appear to be largely systematic to all trained divers rather than having been affected by levels of experience or idiosyncratic factors.

Time-series comparisons during training indicated that some enthusiastic volunteer divers were capable of undertaking valuable biodiversity surveys in the first day of training. Volunteers participating in this project were screened for enthusiasm and dive experience prior to training, and as a consequence represented a relatively small subset of the recreational dive community. Regardless, divers participating in other marine ecological studies that involve less selective processes prior to training have also contributed useful data sets (Darwall \& Dulvy 1996, Schmitt \& Sullivan 1996).

The best divers were also those most prepared for long-term commitment, as indicated by a strong relationship between similarity to trainer data (an index of diver quality) and number of surveys completed subsequent to training. Clearly, the most enthusiastic divers were also the most committed and best educated about local marine life. They knew many of the local species and were well prepared for training courses. Poorly prepared divers and others who struggled during training typically failed to continue with the program.

This self-selection process proved useful for project outcomes because almost all data generated subsequent to training, which was used in analyses of MPA effects, have been provided by the best divers. Through this selection process, support and resources can also be channelled most efficiently to the most skillful of the volunteer divers.

Although the capacity of trained volunteer divers to assist scientific studies is rarely utilised, we suggest that this largely untapped resource possesses huge potential value when assessing patterns over continental and global scales (Hodgson 1999). Over the long term, the focused skill and enthusiasm of recreational divers should not only prove useful for quantifying ecological changes associated with the declaration of MPAs, but also for assessing other broad-scale human 
impacts on the global marine environment including climate change, effects of fishing and invasive species.

Outcomes presented here are based on data obtained during the start-up year of the Reef Life Survey program, and on analyses involving few metrics. Through the longer term, with data from thousands of sites, a much better understanding of the influences of the ecological factors listed in Table 1 that potentially affect reef communities, including interactions and non-linearities in trends, should be possible.

Acknowledgements. We particularly thank N. Barrett, A. Cooper, M. Davey, S. Töpfer, B. Andrewartha, B. Barnes and Reef Life Survey Steering Committee members: A. Green, A. Zacharek, B. McDonald, I. Shaw, J. Brook, K. Bancroft, R. Koss, S. Shepherd and T. Lynch. We also thank all participating divers, particularly T. Davis, A. Green, B. Barker, S. Newson, J. Allen, K. and T. Saunders, M. and A. Smith, D. Love, E. Oh, K. Smith, P. Day, J. Hoskin and T. Forster. The project was supported by funding from the Commonwealth Environment Research Facilities (CERF) program, an Australian Government initiative supporting public good research

\section{LITERATURE CITED}

Anderson MJ (2001) A new method for non-parametric multivariate analysis of variance. Austral Ecol 26:32-46

Anderson MJ, Gorley RN, Clarke KR (2008) PERMANOVA+ for PRIMER: guide to software and statistical methods. PRIMER-E, Plymouth

- Ardron JA (2008) The challenge of assessing whether the OSPAR network of marine protected areas is ecologically coherent. Hydrobiologia 606:45-53

Badalamenti F, Ramos AA, Voultsiadou E, Lizaso JLS and others (2000) Cultural and socio-economic impacts of Mediterranean Marine Protected Areas. Environ Conserv 27:110-125

Baelde P (2005) Interactions between the implementation of marine protected areas and right-based fisheries management in Australia. Fish Manag Ecol 12:9-18

Barrett NS, Edgar GJ, Buxton CD, Haddon M (2007) Changes in fish assemblages following 10 years of protection in Tasmanian marine protected areas. J Exp Mar Biol Ecol 345:141-157

Barrett NS, Buxton CD, Edgar GJ (2009) Changes in invertebrate and macroalgal populations in Tasmanian marine reserves in the decade following protection. J Exp Mar Biol Ecol 370:104-119

Bellwood DR, Hughes TP, Folke C, Nyström M (2004) Confronting the coral reef crisis. Nature 429:827-833

> Bennett I, Pope EC (1960) Intertidal zonation of the exposed rocky shores of Tasmania and its relationship with the rest of Australia. Aust J Mar Freshw Res 11:182-221

Botsford LW, White JW, Coffroth MA, Paris CB and others (2009) Connectivity and resilience of coral reef metapopulations in marine protected areas: matching empirical efforts to predictive needs. Coral Reefs 28:327-337

> Byers JE, Noonburg EG (2007) Poaching, enforcement, and the efficacy of marine reserves. Ecol Appl 17:1851-1856

Cade BS, Noon BR (2003) A gentle introduction to quantile regression for ecologists. Front Ecol Environ 1:412-420

Carr MH, Neigel JE, Estes JA, Andelman S, Warner RR, Largier JL (2003) Comparing marine and terrestrial ecosystems: implications for the design of coastal marine reserves. Ecol Appl 13(Suppl):90-107

Claudet J, Osenberg CW, Benedetti-Cecchi L, Domenici P and others (2008) Marine reserves: size and age do matter. Ecol Lett 11:481-489

Codling EA (2008) Individual-based movement behaviour in a simple marine reserve-fishery system: why predictive models should be handled with care. Hydrobiologia 606: $55-61$

Côté IM, Mosqueira I, Reynolds JD (2001) Effects of marine reserve characteristics on the protection of fish populations: a meta-analysis. J Fish Biol 59(Suppl A):178-189

Cowen RK, Gawarkiewicz G, Pineda J, Thorrold SR, Werner FE (2007) Population connectivity in marine systems: an overview. Oceanography 20:14-21

Crowder LB, Lyman SJ, Figueira WF, Priddy J (2000) Source-sink population dynamics and the problem of siting marine reserves. Bull Mar Sci 66:799-820

Darwall WRT, Dulvy NK (1996) An evaluation of the suitability of non-specialist volunteer researchers for coral reef fish surveys. Mafia Island, Tanzania: a case study. Biol Conserv 78:223-231

Dayton PK, Sala E, Tegner MJ, Thrush S (2000) Marine reserves: parks, baselines, and fishery enhancement. Bull Mar Sci 66:617-634

Edgar GJ, Barrett NS (1999) Effects of the declaration of marine reserves on Tasmanian reef fishes, invertebrates and plants. J Exp Mar Biol Ecol 242:107-144

> Edgar GJ, Shaw C (1995) The production and trophic ecology of shallow-water fish assemblages in southern Australia. II. Diets of fishes and trophic relationships between fishes and benthos at Western Port, Victoria. J Exp Mar Biol Ecol 194:83-106

Edgar GJ, Moverley J, Barrett NS, Peters D, Reed C (1997) The conservation-related benefits of a systematic marine biological sampling program: the Tasmanian reef bioregionalisation as a case study. Biol Cons 79:227-240

Edgar GJ, Barrett NS, Morton AJ (2004) Biases associated with the use of underwater visual census techniques to quantify the density and size-structure of fish populations. J Exp Mar Biol Ecol 308:269-290

Edgar GJ, Russ GR, Babcock RC (2007) Marine protected areas. In: Connell S, Gillanders BM (eds) Marine ecology. Oxford University Press, South Melbourne, p 533-555

Edgar GJ, Barrett NS, Stuart-Smith RD (in press) Exploited reefs protected within marine reserves transform over decades into conservation features otherwise absent from seascapes. Ecol Appl

Eggleston DB, Parsons DM (2008) Disturbance-induced 'spillin' of Caribbean spiny lobster to marine reserves. Mar Ecol Prog Ser 371:213-220

> Faith DP, Minchin PR, Belbin L (1987) Compositional dissimilarity as a robust measure of ecological distance. Vegetatio 69:57-68

Forcada A, Bayle-Sempere JT, Valle C, Sánchez-Jerez P (2008) Habitat continuity effects on gradients of fish biomass across marine protected area boundaries. Mar Environ Res 66:536-547

> Francini-Filho RB, Moura RL (2008) Evidence for spillover of reef fishes from a no-take marine reserve: an evaluation using the before-after control-impact (BACI) approach. Fish Res 93:346-356

Green RH (1979) Sampling design and statistical methods for environmental biologists. Wiley, Chichester

Guidetti P, Sala E (2007) Community-wide effects of marine reserves in the Mediterranean Sea. Mar Ecol Prog Ser 335: $43-56$ 
Guidetti P, Milazzo M, Bussotti S, Molinari A and others (2008) Italian marine reserve effectiveness: Does enforcement matter? Biol Conserv 141:699-709

Halford AR, Perret J (2009) Patterns of recovery in catastrophically disturbed reef fish assemblages. Mar Ecol Prog Ser 383:261-272

> Halpern BS (2003) The impact of marine reserves: Do reserves work and does reserve size matter? Ecol Appl 13(Suppl):117-137

Halpern BS, Warner RR (2002) Marine reserves have rapid and lasting effects. Ecol Lett 5:361-366

> Harmelin-Vivien M, Le Direach L, Bayle-Sempere J, Charbonnel E and others (2008) Gradients of abundance and biomass across reserve boundaries in six Mediterranean marine protected areas: evidence of fish spillover? Biol Conserv 141:1829-1839

Hodgson G (1999) A global assessment of human effects on coral reefs. Mar Pollut Bull 38:345-355

Interim Marine and Coastal Regionalisation for Australia Technical Group (1998) Interim Marine and Coastal Regionalisation for Australia: an ecosystem-based classification for the marine and coastal environments. Version 3.3. Environment Australia, Canberra

> Jennings S, Mélin F, Blanchard JL, Forster RM, Dulvy NK, Wilson RW (2008) Global-scale predictions of community and ecosystem properties from simple ecological theory. Proc R Soc Lond B Biol Sci 275:1375-1383

Kaplan DM (2009) Fish life histories and marine protected areas: an odd couple? Mar Ecol Prog Ser 377:213-225

Kleczkowski M, Babcock RC, Clapin G (2008) Density and size of reef fishes in and around a temperate marine reserve. Mar Freshw Res 59:165-176

Kotiaho JS, Tomkins JL (2002) Meta-analysis, can it ever fail? Oikos 96:551-553

Kritzer JP (2004) Effects of noncompliance on the success of alternative designs of marine protected-area networks for conservation and fisheries management. Conserv Biol 18: 1021-1031

> Le Quesne WJF (2009) Are flawed MPAs any good or just a new way of making old mistakes? ICES J Mar Sci 66: 132-136

Lester SE, Halpern BS (2008) Biological responses in marine no-take reserves versus partially protected areas. Mar Ecol Prog Ser 367:49-56

Little LR, Smith ADM, McDonald AD, Punt AE, Mapstone BD, Pantus F, Davies CR (2005) Effects of size and fragmentation of marine reserves and fisher infringement on the catch and biomass of coral trout, Plectropomus leopardus, on the Great Barrier Reef, Australia. Fish Manag Ecol 12: 177-188

Lynch TP (2006) Incorporation of recreational fishing effort into design of marine protected areas. Conserv Biol 20: 1466-1476

McClanahan TR (2008) Response of the coral reef benthos and herbivory to fishery closure management and the 1998 ENSO disturbance. Oecologia 155:169-177

> Micheli F, Halpern BS, Botsford LW, Warner RR (2004) Trajectories and correlates of community change in no-take marine reserves. Ecol Appl 14:1709-1723

Milazzo M, Badalamenti F, Vega Fernández T, Chemello R (2005) Effects of fish feeding by snorkellers on the density and size distribution of fishes in a Mediterranean marine protected area. Mar Biol 146:1213-1222

- Mora C (2008) A clear human footprint in the coral reefs of the Caribbean. Proc R Soc Lond B Biol Sci 275:767-773

> Mosquera I, Côté IM, Jennings S, Reynolds JD (2000) Conservation benefits of marine reserves for fish populations.
Anim Conserv 3:321-332

Newman MJH, Paredes GA, Sala E, Jackson JBC (2006) Structure of Caribbean coral reef communities across a large gradient of fish biomass. Ecol Lett 9:1216-1227

> Pederson HG, Johnson CR (2006) Predation of the sea urchin Heliocidaris erythrogramma by rock lobsters (Jasus edwardsii) in no-take marine reserves. J Exp Mar Biol Ecol 336:120-134

> Preuss B, Pelletier D, Wantiez L, Letourneur Y and others (2009) Considering multiple-species attributes to understand better the effects of successive changes in protection status on a coral reef fish assemblage. ICES J Mar Sci 66:170-179

Richardson AJ, Poloczanska ES (2008) Ocean science: underresourced, under threat. Science 320:1294-1295

Russ GR (2002) Yet another review of marine reserves as reef fisheries management tools. In: Sale PF (ed) Coral reef fishes: dynamics and diversity in a complex ecosystem. Academic Press, San Diego, CA, p 421-443

Russ GR, Cheal AJ, Dolman AM, Emslie MJ and others (2008) Rapid increase in fish numbers follows creation of world's largest marine reserve network. Curr Biol 18:R514-R515

Schmitt EF, Sullivan KM (1996) Analysis of a volunteer method for collecting fish presence and abundance data in the Florida Keys. Bull Mar Sci 59:404-416

Sethi SA, Hilborn R (2008) Interactions between poaching and management policy affect marine reserves as conservation tools. Biol Conserv 141:506-516

Shears NI, Babcock RI (2002) Marine reserves demonstrate top-down control of community structure on temperate reefs. Oecologia 132:131-142

Shears NT, Babcock RC (2003) Continuing trophic cascade effects after 25 years of no-take marine reserve protection. Mar Ecol Prog Ser 246:1-16

> Sweatman H (2008) No-take reserves protect coral reefs from predatory starfish. Curr Biol 18:R598-R599

> Tetreault I, Ambrose RF (2007) Temperate marine reserves enhance targeted but not untargeted fishes in multiple notake MPAs. Ecol Appl 17:2251-2267

> Tomkins JL, Kotiaho JS (2004) Publication bias in meta-analysis: seeing the wood for the trees. Oikos 104:194-196

Walters C (2000) Impacts of dispersal, ecological interactions, and fishing effort dynamics on efficacy of marine protected areas: How large should protected areas be? Bull Mar Sci 66:745-757

- Walters CJ, Holling CS (1990) Large-scale management experiments and learning by doing. Ecology 71:2060-2068

> Wantiez L, Thollot P, Kulbicki M (1997) Effects of marine reserves on coral reef fish communities from five islands in New Caledonia. Coral Reefs 16:215-224

Werner FE, Cowen RK, Paris CB (2007) Coupled biological and physical models: present capabilities and necessary developments for future studies of population connectivity. Oceanography 20:54-69

Wiens JA (1989) Spatial scaling in ecology. Funct Ecol 3: 385-397

- Williams ID, Walsh WJ, Miyasaka A, Friedlander AM (2006) Effects of rotational closure on coral reef fishes in WaikikiDiamond Head Fishery Management Area, Oahu, Hawaii. Mar Ecol Prog Ser 310:139-149

Willis TJ, Millar RB, Babcock RC, Tolimieri N (2003) Burdens of evidence and the benefits of marine reserves: putting Descartes before des horse? Environ Conserv 30:97-103

Winer BJ, Brown DR, Michels KM (1991) Statistical principles in experimental design, 3rd edn. McGraw-Hill, New York

Wolff M (2002) Concepts and approaches for marine ecosystem research with reference to the tropics. Rev Biol Trop 50:395-414 